\title{
Cross-cultural development of an EORTC questionnaire to assess health-related quality of life in patients with testicular cancer: the EORTC QLQ-TC26
}

\author{
Bernhard Holzner • Fabio Efficace • Umberto Basso • Colin D. Johnson • \\ Neil K. Aaronson • Juan I. Arraras • Allan B. Smith • Edward Chow • \\ Anne S. Oberguggenberger • Andrew Bottomley • Hannes Steiner • \\ Luca Incrocci · Johannes M. Giesinger
}

Accepted: 20 February 2012/Published online: 10 March 2012

(C) The Author(s) 2012. This article is published with open access at Springerlink.com

\begin{abstract}
Objective Testicular cancer (TC) is the most common cancer in young men, and its incidence is increasing. The low mortality rate makes quality of life (QOL) an important issue in this patient group. This study aimed to develop a supplementary module of the EORTC QLQ-C30 questionnaire to assess TC-specific aspects of QOL.
\end{abstract}

This study is conducted on behalf of the European Organisation for Research and Treatment of Cancer Quality of Life Group (EORTCQLG).

B. Holzner · A. S. Oberguggenberger · J. M. Giesinger $(\square)$ Department of Psychiatry and Psychotherapy, Innsbruck Medical University, Anichstr. 35, 6020 Innsbruck, Austria

e-mail: johannes.giesinger@i-med.ac.at

B. Holzner

e-mail: bernhard.holzner@uki.at

A. S. Oberguggenberger

e-mail: anne.oberguggenberger@uki.at

F. Efficace

Health Outcomes Research Unit, Italian Group for Adult

Hematologic Diseases (GIMEMA) Data Center, Rome, Italy

e-mail: f.efficace@gimema.it

U. Basso

Medical Oncology 1, Istituto Oncologico Veneto

(IOV) IRCCS, Padua, Italy

e-mail: u.basso@tin.it

U. Basso

Italian Germ Cell Cancer Group (IGG), Padua, Italy

C. D. Johnson

University Surgical Unit, Southampton University Hospitals, University of Southampton, Tremona Road, Southampton

SO16 6YD, UK

e-mail: c.d.johnson@soton.ac.uk
Methods Questionnaire development was conducted according to guidelines from the EORTC Quality of Life Group. Phase I comprised generation of QOL issues relevant to TC patients through a literature search and interviews with patients and experts. Phase II included operationalization and assessment of item relevance. In phase III, items were pre-tested in a cross-cultural sample to assess issues such as understandability and intrusiveness of items.

Results In phase I and II, an initial list of 69 QOL issues possibly relevant to TC patients was refined through patient and expert interviews. The remaining 37 issues were

\section{N. K. Aaronson}

Division of Psychosocial Research and Epidemiology,

The Netherlands Cancer Institute, Plesmanlaan 121,

1066 CX Amsterdam, The Netherlands

e-mail:n.aaronson@nki.nl

\section{J. I. Arraras}

Medical Oncology Department, Hospital of Navarre,

C/Irunlarrea 3, 31008 Navarre, Pamplona, Spain

e-mail: jiarraras@correo.cop.es

\author{
A. B. Smith \\ Psycho-Oncology Co-operative Research Group, School \\ of Psychology, University of Sydney, Sydney, NSW 2006, \\ Australia \\ e-mail: allan.smith@sydney.edu.au \\ E. Chow \\ Department of Radiation Oncology, Toronto Sunnybrook \\ Regional Cancer Centre, 2075, Bayview Avenue, \\ Toronto, ON M4N 3M, Canada \\ e-mail: edward.chow@tsrcc.on.ca
}

A. Bottomley

EORTC Headquarters Quality of Life Department,

Ave. E. Mounier 83, 111200 Brussels, Belgium

e-mail: andrew.bottomley@eortc.be 
operationalized into items and assessed for relevance and priority in an expert sample $(n=28)$ and a patient sample $(n=62)$ from Austria, Canada and the Netherlands. After revision of the item list, 26 items were considered eligible for pre-testing in phase III, in which 156 patients from Australia, Austria, Italy and Spain participated. All items passed criteria for pre-testing, thus forming the new EORTC QLQ-TC26.

Conclusion The newly developed EORTC QLQ-TC26 is now available in several languages to assess QOL in TC patients receiving treatment and in TC survivors. Phase IV of questionnaire development will comprise international field testing, including extensive analysis of psychometric characteristics of the EORTC QLQ-TC26.

Keywords Testicular cancer - Quality of life . Questionnaire · eortc qlq-tc26

\begin{tabular}{|c|c|}
\hline \multicolumn{2}{|c|}{ Abbreviations } \\
\hline EORTC & $\begin{array}{l}\text { European Organisation for Research } \\
\text { and Treatment of Cancer }\end{array}$ \\
\hline FACT-G & $\begin{array}{l}\text { Functional assessment of cancer } \\
\text { therapy_general }\end{array}$ \\
\hline GHQ-28 & General Health Questionnaire-28 \\
\hline QLQ-C30 & Quality of Life Questionnaire-Core 30 \\
\hline QOL & Quality of life \\
\hline SD & Standard deviation \\
\hline $\mathrm{TC}$ & Testicular cancer \\
\hline
\end{tabular}

\section{Introduction}

Testicular cancer (TC) is the most common type of cancer in men aged 15-45 years, and its incidence is increasing [1, 2]. Due to the high survival rate in this cancer population, preserving quality of life (QOL) and minimizing adverse effects of cancer therapy are major issues [3-5]. These issues are particularly important as testicular cancer typically occurs as men are approaching the peak of their personal and professional lives, when fertility and family life are of utmost importance [6].

Treatment for TC usually comprises orchiectomy, with subsequent therapy depending on tumour histology and

\footnotetext{
H. Steiner

Center of Operative Medicine, Innsbruck Medical University, Anichstr. 35, 6020 Innsbruck, Austria

e-mail: hannes.steiner@uki.at

L. Incrocci

Department of Radiation Oncology, Erasmus MC-Daniel Den

Hoed Cancer Center, Rotterdam, The Netherlands

e-mail: 1.incrocci@erasmusmc.nl
}

stage [7]. Patients with seminomas often receive additional radiotherapy [8], but also carboplatin-based chemotherapy has been shown to be a good alternative for stage I seminomas [9]. Chemotherapy with bleomycin, etoposide and cisplatin shows very good results for non-seminomas and seminomas with a stage higher than I [10]. Another therapy option in case of residual tumour mass after chemotherapy is retroperitoneal lymph node dissection with nerve sparing $[2,11]$.

To date, studies of symptom burden in TC patients have generally focused on survivors, highlighting a range of persistent impairments. Physical impairments relating to chemotherapy side effects include Raynaud's phenomena [12, 13], tinnitus [12] and long-term effects such as increased incidence of cardiovascular disease [14, 15]. Both chemotherapy and radiotherapy impact infertility [16] and lead to increased fatigue levels [3].

TC survivors' sexual functioning is impacted by gonadal dysfunction [17, 18], decreased libido [19], dry ejaculation [5, 19] and other sexual difficulties [20]. Fegg et al. [19] also argue that sexual concerns are further aggravated by inadequate communication about these issues between doctors and patients. Ozen et al. [21] contend that libido and erectile dysfunction improved post-treatment, but did not reach pre-treatment levels. In contrast, ejaculation problems increased further after cessation of treatment.

To date, a limited number of questionnaires have been specifically validated for use in TC patients, for example, to assess neurotoxicity [22], coping [23], marital and sexual satisfaction [24], and QOL [25]. In particular, the QOL questionnaire developed by Fossa et al. [25] was an important step towards the comprehensive assessment of symptoms and functioning in TC patients. This questionnaire has already been used to measure outcomes in an international trial of the European Organisation for Research and Treatment of Cancer (EORTC) investigating QOL in patients with metastatic germ cell cancer [12]. However, as mentioned by Fossa et al. [12], psychometric testing and extensive translation checks for this questionnaire have not been undertaken. Also, its development did not follow the detailed EORTC guidelines for questionnaire development guaranteeing cross-cultural applicability and compatibility with the EORTC QLQ-C30. The EORTC approach to QOL assessment is to use the EORTC QLQ-C30 for assessing general aspects of QOL that are relevant to (almost) all cancer patients and to supplement this core questionnaire with disease-specific questionnaire modules. So far, a questionnaire module for TC patients was lacking, limiting the use of the EORTC QOL measurement system with regard to this patient group.

Thus, the aim of this project was to develop a questionnaire module as a supplement to the EORTC QLQ-C30 to assess QOL of TC patients in clinical trials and daily 
clinical practice. This questionnaire module was designed to be applicable to both patients undergoing treatment and cancer survivors and covers TC-specific issues such as common treatment side effects, infertility, body image and sexuality.

\section{Methods}

Our study followed the EORTC guidelines for developing questionnaire modules [26]. These guidelines comprise four phases: (1) generation of relevant QOL issues, (2) operationalization of the QOL issues into a set of items, (3) pre-testing the questionnaire module and (4) large-scale international field testing.
Phase I-III has now been completed, and the results from each are presented within this manuscript. The main steps of the whole development process are summarized in Fig. 1.

Phase I and II: Generation of relevant QOL issues and operationalization

An extensive literature search was conducted to establish an initial list of QOL issues potentially relevant to TC patients. This list was evaluated in semi-structured interviews with experts in the field and with patients to clarify whether further issues should be included.

The literature search in the databases MEDLINE and PsychINFO covered the years 1996 to 2006. The following
Fig. 1 Flowchart of the module development process for the QLQ-TC26 (according to $[26,37])$
Phase I and II (Generation of QOL issues relevant to patients and operationalisation) Systematic literature review (37 articles and 20 Questionnaires with relevant QOL issues)

69 QOL issues: correction for overlap and discussion at two EORTC Quality of Life Group (QLG) Meetings

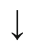

Reduction to 37 QOL issues (see Table 1)

$\downarrow$

Brought-forward phase II: Consultation with the EORTC QLG Item Bank for existing items

Translation of items according to EORTC QLG guidelines<smiles>[AlH]</smiles>

Semi-structured interviews with patients $(n=62)$

Semi-structured interviews with experts in the field $(n=28)$

$\downarrow$

Quantitative \& qualitative analysis of interview data

Review of items by QLG Module Development Team

$\downarrow$

Item revision and reduction to 26 items (see Table 5)

$\downarrow$

Phase III (Testing the provisional item list for relevance and acceptability)

Completion of EORTC QLQ-C30 \& the 26 provisional TC item

by patients $(n=156)$

$\downarrow$

Quantitative \& qualitative analysis

Review of analysis by QLG Module Development Team

Peer review of module development process by EORTC QLG

EORTC QLQ-TC26 
keywords were used: (testis OR testicular) AND (carcinoma OR cancer OR neoplasm) AND (quality of life OR health status OR side effects OR long-term effects OR symptoms OR radiotherapy OR chemotherapy OR surgery OR anxiety OR sexuality OR infertility OR body image OR body mass index, weight change OR information OR treatment satisfaction OR insurance OR future perspective/ uncertainty).

At this point, we brought forward operationalization of items (phase II) usually done after phase I to conduct assessments of specific item text already in patients and experts already at this stage. QOL issues collected so far were operationalized into items using a response format and time frame compatible with the EORTC QLQ-C30. Pre-existing items from the EORTC Quality of Life Group Item Bank (covering all items from all development stages of EORTC modules) were used where possible [27]. The English items were then translated into the languages of participating centres to allow collection of patient and expert ratings. Translation was done according to the EORTC translation procedure guidelines [28].

Expert and patient ratings of each item were collected for the following criteria:

- Relevance was rated for each item on a four-point scale, ranging from "not at all relevant" (1 point) to "very much relevant" (4 points). Relevance refers to the frequency with which a problem or symptom occurs and the trouble it may cause.

- Priority for inclusion was rated for each item to identify those items that affect patients' QOL most and that should definitely be included in the final questionnaire.

- Breadth of coverage was investigated by asking patients and experts to suggest any relevant issues not included in the item list that should be added.

Items were eligible for inclusion if the mean relevance scores of patients and of specialists (considered separately) were 2 or greater and at least $40 \%$ of patients and $40 \%$ of specialists gave priority for inclusion. Furthermore, items were excluded if more than $25 \%$ of the answers were missing (this criterion was not applied to conditional items). These selection criteria for relevance and priority are similar to those used in phase I of other EORTC module development studies [29-31].

Ethical approval was obtained from local ethics committees at centres contributing patients to phase I and/or phase III.

Phase III: pre-testing of the module

The pre-testing of the module in a sample of TC patients from different countries and with different languages aimed to identify potential problems regarding wording, comprehensiveness and redundancy or duplications. Patients were encouraged to comment on each question (e.g. was it difficult to answer, annoying, confusing, upsetting or intrusive) and to provide additional concerns or relevant QOL issues not mentioned in the questionnaire.

Retention criteria for phase III related to patient comments. Items were retained if $<10 \%$ of patients made any negative comments about an item and if $<5 \%$ of patients made the same negative comment about an item (e.g. $<5 \%$ of patients complained about an item being difficult).

In addition, descriptive statistics and preliminary psychometric characteristics for a provisional, content-based subscale structure were determined. Scores have been linearly transformed to a scale range of $0-100$, as is common for EORTC scales.

\section{Results}

Phase I and II: generation of relevant QOL issues and operationalization

The literature search revealed 37 articles and 26 questionnaires providing QOL issues relevant to TC patients. Based on this literature search and expert discussion, we assembled an initial list of 20 QOL areas containing 69 issues of potential relevance to TC patients. This list was edited to remove overlap and redundancy and was assessed by means of a semi-structured interview with experts in the field at two EORTC Quality of Life Group Meetings in 2006. These experts came from various countries (Austria, Belgium, Brazil, Germany, Italy, the Netherlands, Norway, Poland and the UK). Based on this selection procedure, we reduced the number of QOL issues on the list to 37 (see Table 1).

The 37 issues were operationalized into items with a response format and time frame compatible with the QLQC30 (as mentioned above, we conducted phase I and II concurrently). For 25 issues, there were items available from the EORTC item bank. New items were created to assess the other 12 issues. These items were translated into Dutch, German, Italian and Spanish and evaluated by patients and experts.

Expert ratings on relevance, priority and breadth of coverage were collected from 28 experts (11 urologists, 6 radiation oncologists, 3 psychologists, 2 medical oncologists, 2 physicians, 2 junior physicians, a nurse and an urologist in training). They were working at centres in Austria (10), the Netherlands (7), Italy (7), Canada (3) and England (1). Their average years of professional experience was 11.9 (range 1-35). Items were rated separately for patients receiving treatment and patients after treatment.

The patient group for item evaluation included 62 TC patients from Austria $(n=39)$, Canada $(n=12)$ and the 
Table 1 QOL issues identified in phase I

\begin{tabular}{|c|c|}
\hline QOL area & Issue \\
\hline $\begin{array}{l}\text { Treatment-related symptoms } \\
\text { (in particular, chemotherapy) }\end{array}$ & $\begin{array}{l}\text { 1. Hair loss } \\
\text { 2. Different taste } \\
\text { 3. Sense of taste and smell }\end{array}$ \\
\hline $\begin{array}{l}\text { Treatment-related symptoms } \\
\text { (in particular, radiotherapy) }\end{array}$ & $\begin{array}{l}\text { 4. Abdominal pain } \\
\text { 5. Heartburn } \\
\text { 6. Bloated feeling } \\
\text { 7. Change in bowel habit } \\
\text { 8. Skin problems } \\
\text { 9. Irradiated skin discoloured }\end{array}$ \\
\hline Peripheral neuropathy & $\begin{array}{l}\text { 10. Tingling or numbness } \\
\text { fingers/toes } \\
\text { 11. Pale/cold fingers/toes } \\
\text { 12. Burning/pain in fingers/toes }\end{array}$ \\
\hline Difficulty in hearing/tinnitus & 13. Problems with hearing \\
\hline $\begin{array}{l}\text { Satisfaction with medical } \\
\text { management }\end{array}$ & 14. Satisfied with care received \\
\hline $\begin{array}{l}\text { Satisfaction with received } \\
\text { information }\end{array}$ & $\begin{array}{l}\text { 15. Satisfied with information } \\
\text { received }\end{array}$ \\
\hline Future uncertainty & 16. Uncertain about future \\
\hline Loan/Insurance & $\begin{array}{l}\text { 17. Loan/insurance problems } \\
\text { 18. Problems with job }\end{array}$ \\
\hline Anxiety of recurrence & 19. Anxious about a recurrence \\
\hline Anxiety of family disruption & 20. Disruption of family life \\
\hline Communication & $\begin{array}{l}\text { 21. Talk about disease with } \\
\text { partner }\end{array}$ \\
\hline Activity & 22. Physically limited \\
\hline Infertility & 23. Ability to have children \\
\hline Body image & $\begin{array}{l}\text { 24. Less masculine } \\
\text { 25. Look at yourself naked } \\
\text { 26. Dissatisfied with body } \\
\text { 27. Satisfied with testicular } \\
\text { implant }\end{array}$ \\
\hline Weight change & $\begin{array}{l}\text { 28. Lost weight } \\
\text { 29. Gained weight }\end{array}$ \\
\hline Sexual activity & $\begin{array}{l}\text { 30. Interested in sex } \\
\text { 31. Sexually active }\end{array}$ \\
\hline Sexual functioning & $\begin{array}{l}\text { 32. Felt uncomfortable being } \\
\text { intimate } \\
\text { 33. Talk about sexuality } \\
\text { 34. Difficulty getting an erection } \\
\text { 35. Problems with ejaculation }\end{array}$ \\
\hline Sexual enjoyment & 36. Was sex enjoyable? \\
\hline $\begin{array}{l}\text { Satisfaction with the sexual } \\
\text { relationship }\end{array}$ & $\begin{array}{l}\text { 37. Satisfied with sexual } \\
\text { relationship }\end{array}$ \\
\hline
\end{tabular}

Netherlands $(n=11)$, with a mean age of 39.8 (SD 10.9). Detailed sociodemographic and clinical data are shown in Table 2.

Twenty-six of the 37 items met all inclusion criteria relating to priority, relevance and breadth of coverage. The remaining 11 items failed to meet one criterion, mainly patient-rated relevance.

Comments by patients were very rare and therefore did not have a substantial impact on item selection and item wording. There were several comments from specialists regarding the content/wording of items (for item numbers refer to Table 3). Several items were revised based on the data collected. For example:

- Item 4 "Did you have abdominal pain?" was changed to "Did you have pain in your stomach area?" to increase understandability.

- Item 7 "Did you experience change in bowel habit as a result of your disease or treatment?" was deleted as this issue is already covered by the QLQ-C30 questions on diarrhoea and constipation.

- Item 10 "Have you had tingling or numbness in your fingers or toes?" was retained, although patients rated the relevance of this item slightly below two. However, high expert-rated relevance provided grounds for inclusion.

- Item 13 "Did you have problems with hearing?" also received a relevance rating below two from patients, but high relevance ratings from experts supported inclusion.

- Item 18 "Have you had any problems with your job because of your illness?"was amended to include education, since a high percentage of patients with TC are quite young and may be still studying. Furthermore, we changed the term "illness" to "disease or treatment" to be consistent with other items.

- Item 24 "Have you felt less masculine as a result of your disease or treatment?" was retained, despite narrowly failing to meet the patient relevance criterion, because otherwise the module would not have covered the area of body image at all. This item was rated as highly relevant by specialists.

- Items 28 and 29 concerning weight gain and weight loss were deleted for several reasons. Experts considered it more appropriate to measure weight change using body mass index; weight change over a short period such as 4 weeks may be negligible for patients off-treatment (note that a different time frame was used for these two items); and weight gain and weight loss can not be combined in a meaningful single scale.

Phase III: pre-testing of the module

The provisional TC module (EORTC QLQ-TC26) derived from phase II was pre-tested in four countries. From December 2008 to May 2010, a prospective sample of 156 TC patients was recruited in Austria $(n=74)$, Italy $(n=35)$, Spain $(n=15)$ and Australia $(n=32)$. Mean patient age was 36.8 years (SD 10.5), and mean time since 
Table 2 Phase I and III: Sociodemographic and clinical data for the module development samples

\begin{tabular}{|c|c|c|c|}
\hline & & $\begin{array}{l}\text { Phase I sample } \\
n=62\end{array}$ & $\begin{array}{l}\text { Phase III sample } \\
n=156\end{array}$ \\
\hline \multirow[t]{6}{*}{ Country (language) } & Australia (English) & - & $20.5 \%$ \\
\hline & Austria (German) & $62.9 \%$ & $47.4 \%$ \\
\hline & Canada (English) & $19.4 \%$ & - \\
\hline & Italy (Italian) & - & $22.4 \%$ \\
\hline & the Netherlands (Dutch) & $17.7 \%$ & - \\
\hline & Spain (Spanish) & - & $9.6 \%$ \\
\hline \multirow[t]{2}{*}{ Age (years) } & Mean (SD) & $39.8(10.9)$ & $36.8(10.5)$ \\
\hline & Range & $21-63$ & $18-66$ \\
\hline \multirow[t]{4}{*}{ Education } & Compulsory school or less & $10.9 \%$ & $14.2 \%$ \\
\hline & Apprenticeship or professional & $34.5 \%$ & $29.1 \%$ \\
\hline & School & $38.2 \%$ & $22.8 \%$ \\
\hline & A-level university degree & $16.4 \%$ & $33.9 \%$ \\
\hline \multirow[t]{4}{*}{ Marital status } & Single & $31.0 \%$ & $29.3 \%$ \\
\hline & Married/partnership & $62.1 \%$ & $65.3 \%$ \\
\hline & Divorced/separated & $5.2 \%$ & $4.0 \%$ \\
\hline & Widowed & $1.7 \%$ & $1.3 \%$ \\
\hline \multirow[t]{5}{*}{ Employment } & Full-time & $75.4 \%$ & $86.7 \%$ \\
\hline & Part-time & $7.0 \%$ & $1.7 \%$ \\
\hline & In training & $3.5 \%$ & $5.0 \%$ \\
\hline & Unemployed & $7.0 \%$ & $2.5 \%$ \\
\hline & Other & $7.0 \%$ & $4.1 \%$ \\
\hline \multirow[t]{3}{*}{ Treatment phase } & On treatment & $18.6 \%$ & $21.0 \%$ \\
\hline & $<1$ st year of aftercare & $14.0 \%$ & $35.0 \%$ \\
\hline & $>1$ st year of aftercare & $67.4 \%$ & $44.1 \%$ \\
\hline \multirow[t]{2}{*}{ Tumour stage } & Local & $73.6 \%$ & $74.8 \%$ \\
\hline & Advanced & $26.4 \%$ & $25.2 \%$ \\
\hline \multirow[t]{2}{*}{ Surgery } & Yes & $91.2 \%$ & $91.0 \%$ \\
\hline & No & $8.8 \%$ & $9.0 \%$ \\
\hline \multirow[t]{2}{*}{ Radiotherapy } & Yes & $36.8 \%$ & $10.2 \%$ \\
\hline & No & $63.2 \%$ & $89.8 \%$ \\
\hline \multirow[t]{2}{*}{ Chemotherapy } & Yes & $47.4 \%$ & $60.5 \%$ \\
\hline & No & $52.6 \%$ & $39.5 \%$ \\
\hline
\end{tabular}

diagnosis was 12.7 months (SD 14.8). Advanced disease was diagnosed in $25.2 \%$ of patients. For further details on patient characteristics see Table 2 .

From the 156 patients who had been interviewed and had completed the questionnaire, 122 patients $(78.2 \%)$ made no comments, whereas 34 patients (21.8\%) commented on at least on one item. In total, patients provided 26 item-specific and 12 general comments.

Four patients $(2.6 \%)$ found at least one question difficult to understand or answer (item 6 on skin problems and item 7 on pale/cold fingers), and nine patients (5.8\%) reported at least one question to be upsetting, annoying or intrusive (items concerning sexuality, future uncertainty and body image). General comments related to the time frame of 7 days being too short and that questionnaires specific to treatment phases would be preferable. One new issue was raised referring to the need for information on sperm banking. It was agreed that this issue is of high importance before the start of treatment, but no new item was added, since we considered this issue to be covered by item 10 on satisfaction with the information received. The two patients commenting on item 7 (pale/cold fingers) were found to be patients in aftercare who had not undergone chemotherapy. The items on future perspective were considered important as they cover an important psychological parameter commonly assessed in cancer patients.

Overall, patients made only a low number of comments indicating good acceptance and understandability of the items. All items fulfilled the retention criteria stated in the methods section. 
Table 3 Phase I: patient and expert ratings of item relevance and priority for inclusion

\begin{tabular}{|c|c|c|c|c|c|}
\hline & \multirow[t]{2}{*}{ Phase II items } & \multirow{2}{*}{$\begin{array}{l}\text { Relevance } \\
\text { ratings } \\
\text { (mean) } \\
\text { Patients }\end{array}$} & \multicolumn{3}{|c|}{ Priority for inclusion (frequency) } \\
\hline & & & $\begin{array}{l}\text { Specialists off-/ } \\
\text { on-treatment }\end{array}$ & $\begin{array}{l}\text { Patients } \\
(\%)\end{array}$ & $\begin{array}{l}\text { Specialists off-/ } \\
\text { on-treatment }(\%)\end{array}$ \\
\hline 1. & Did you have hair loss? & 2.58 & $2.45 / 2.69$ & 75 & $65 / 71$ \\
\hline 2 & ${ }^{\mathrm{a}}$ Did food and drink taste different from usual? & 2.47 & $2.05 / 2.21$ & 76 & $36 / 31$ \\
\hline 3 & Have you had problems with your sense of taste or smell? & 2.19 & $2.50 / 2.67$ & 73 & $52 / 56$ \\
\hline 4. & Did you have abdominal pain? & 2.06 & $2.55 / 2.88$ & 63 & $69 / 76$ \\
\hline 5 & Have you had heartburn? & 2.04 & $2.45 / 2.94$ & 53 & $65 / 71$ \\
\hline 6 & ${ }^{\mathrm{a}}$ Did you have a bloated feeling in your abdomen? & 1.90 & $2.25 / 2.60$ & 57 & $58 / 71$ \\
\hline 7 & $\begin{array}{l}{ }^{c} \text { Did you experience change in bowel habit as a result } \\
\text { of your disease or treatment? }\end{array}$ & 2.34 & $2.36 / 3.00$ & 65 & $69 / 76$ \\
\hline 8 & Have you had skin problems (e.g. itchy, dry)? & 2.02 & $2.55 / 2.94$ & 65 & $64 / 65$ \\
\hline 9 & ${ }^{\mathrm{a}}$ Is the skin discoloured around the area that was irradiated? & 1.98 & $2.23 / 2.44$ & 62 & $52 / 53$ \\
\hline 10 & ${ }^{\mathrm{b}}$ Have you had tingling or numbness in your fingers or toes? & 1.93 & $2.75 / 2.87$ & 72 & $76 / 75$ \\
\hline 11 & Have you had pale/cold fingers or toes? & 2.00 & $2.38 / 2.60$ & 68 & $60 / 69$ \\
\hline 12 & ${ }^{\mathrm{a}}$ Did you have burning and/or pain in your fingers or toes? & 1.68 & $2.43 / 2.67$ & 58 & $56 / 69$ \\
\hline 13 & ${ }^{\mathrm{b}}$ Did you have problems with hearing? & 1.69 & $2.81 / 2.53$ & 56 & $68 / 69$ \\
\hline 14 & Were you satisfied with the care you received from your doctors? & 3.56 & $3.27 / 3.56$ & 92 & $73 / 94$ \\
\hline 15 & $\begin{array}{l}\text { Were you satisfied with the information you received } \\
\text { about your illness? }\end{array}$ & 3.37 & $2.91 / 3.75$ & 84 & $76 / 100$ \\
\hline 16 & Did you feel uncertain about the future? & 2.68 & $2.91 / 3.13$ & 83 & $65 / 82$ \\
\hline 17 & ${ }^{\mathrm{a}}$ Did you have any loan/insurance problems? & 2.11 & $1.82 / 1.88$ & 58 & $46 / 29$ \\
\hline 18 & Have you had any problems with your job because of your illness? & 2.00 & $2.48 / 2.88$ & 67 & $72 / 71$ \\
\hline 19 & Have you been anxious about a possible recurrence of the disease? & 2.91 & $3.50 / 3.31$ & 94 & $96 / 82$ \\
\hline 20 & Were you concerned about disruption of family life? & 2.49 & $2.86 / 3.31$ & 79 & $60 / 76$ \\
\hline 21 & $\begin{array}{l}\text { Can you talk about your disease with your partner or the person } \\
\text { who is closest to you? }\end{array}$ & 3.52 & $3.00 / 3.50$ & 94 & $62 / 88$ \\
\hline 22 & $\begin{array}{l}\text { Have you been physically limited as a result of your } \\
\text { disease or treatment? }\end{array}$ & 2.41 & $3.09 / 3.31$ & 90 & $85 / 100$ \\
\hline 23 & Were you concerned about your ability to have children? & 2.43 & $3.41 / 3.81$ & 87 & $92 / 100$ \\
\hline 24 & ${ }^{\mathrm{b}}$ Have you felt less masculine as a result of your disease or treatment? & 1.90 & $3.14 / 3.38$ & 71 & $65 / 82$ \\
\hline 25 & ${ }^{a}$ Did you find it difficult to look at yourself naked? & 1.63 & $2.64 / 3.13$ & 49 & $42 / 71$ \\
\hline 26 & ${ }^{\mathrm{a}}$ Have you been dissatisfied with your body? & 1.79 & $2.77 / 3.06$ & 52 & $54 / 71$ \\
\hline 27 & $\begin{array}{l}\text { Answer the question only if you have a testicular implant: } \\
\text { Are you satisfied with your testicular implant? }\end{array}$ & 3.00 & $3.22 / 3.60$ & 79 & $87 / 83$ \\
\hline 28 & ${ }^{\mathrm{c}}$ Have you lost weight? & 2.14 & $2.81 / 2.53$ & 83 & $72 / 47$ \\
\hline 29 & ${ }^{\mathrm{c}}$ Have you gained weight? & 2.05 & $2.76 / 2.44$ & 76 & $64 / 41$ \\
\hline 30 & To what extent were you interested in sex? & 3.02 & $2.95 / 3.19$ & 88 & $84 / 81$ \\
\hline 31 & To what extent were you sexually active? (with or without intercourse) & 2.66 & $2.64 / 2.69$ & 84 & $73 / 71$ \\
\hline 32 & ${ }^{\mathrm{a}}$ Have you felt uncomfortable about being sexually intimate? & 1.98 & $2.95 / 3.13$ & 71 & $69 / 82$ \\
\hline 33 & $\begin{array}{l}\text { Can you talk about sexuality with your partner or the person } \\
\text { who is closest to you? }\end{array}$ & 3.28 & $2.91 / 3.31$ & 88 & $69 / 76$ \\
\hline 34 & Did you have difficulty getting or maintaining an erection? & 2.17 & $3.23 / 3.13$ & 84 & $85 / 71$ \\
\hline 35 & Did you have problems with ejaculation (e.g. dry ejaculation)? & 2.17 & $3.14 / 2.94$ & 81 & $85 / 71$ \\
\hline 36 & To what extent was sex enjoyable for you? & 3.20 & $2.32 / 2.38$ & 87 & $46 / 53$ \\
\hline 37 & Has the sexual relationship with your partner been satisfying? & 3.29 & $2.59 / 2.63$ & 85 & $58 / 65$ \\
\hline
\end{tabular}

${ }^{a}$ Exclusion due to failing at least one retention criterion

${ }^{b}$ Inclusion despite failing retention criteria, due to expert comments

${ }^{c}$ Exclusion due to expert comments, despite fulfilling retention criteria 
Preliminary subscale structure

We conducted a psychometric analysis for a preliminary content-based subscale structure of the TC module (results are shown in Table 4). Most scales showed moderate to good internal consistency, but for the scales Sexual Enjoyment and Sexual Problems, internal consistency was relatively low. Detailed analysis revealed that this was most likely due to strong floor/ceiling effects and therefore limited item variance. As content appeared to be homogeneous, we decided to keep these scales at this stage.

Descriptive statistics for the proposed subscales are given in Table 4 separately for patients in different treatment phases.

\section{Discussion}

The EORTC QLQ-TC26 has been developed to measure disease and treatment-related QOL issues relevant to TC patients that are not covered by the EORTC QLQ-C30. The new module is designed to be administered together with the EORTC QLQ-C30. Module development in phase I, II and III was based on extensive literature search, and ratings and comments from experts and patients and followed the rigorous validation procedures of the EORTC Quality of Life Group [26]. To enhance cross-cultural applicability, patients from various European countries, Australia and Canada were included in the development process.

Across all development phases, we found that patients provided only a relatively small number of comments regarding items, whereas expert feedback and ratings contributed considerably to decisions on in/exclusion of items in the final version of the questionnaire. The low number of comments from patients indicating high acceptance may be due to the fact that a high proportion of items were derived from the EORTC item bank and had consequently already undergone selection procedures within other EORTC module development studies. As expected, a few patients expressed problems answering items on sexuality. Such items are well known to be problematic as they are inherently intrusive to some degree. This is often reflected by low response rates in clinical studies and has been found in other questionnaire development studies [29, 32, 33]. However, sexual functioning and sexual problems are important issues for TC patients and expected to have a particularly high impact on patients' QOL. Therefore, these items were kept in the questionnaire module.

For QOL issue generation in phase I, we screened not only existing questionnaires specific to TC patients or to sexuality (e.g. the QOL questionnaire from Fossa et al. [25], and the Prostate Cancer Sexual Scale [34]), but also generic questionnaires (e.g. FACT-G [35] and the GHQ-28 [36]). As expected, multi-phase item refinement resulted in exclusion of most issues from generic questionnaires, as these were either covered by the EORTC QLQ-C30 core questionnaire or were only of minor relevance to TC patients. Due to the extensive nature of the initial item list generated in phase I, no new issues were included in phase III.

The questionnaire was developed for use not only in patients currently receiving treatment, but also in long-term survivors, that is, patients five or more years after treatment.

Table 4 Proposed subscale structure for the QLQ-TC26 after phase III, with internal consistency statistics (Cronbach's alpha) and descriptive statistics (item numbers refer to Table 5)

\begin{tabular}{|c|c|c|c|c|c|c|c|c|c|c|}
\hline & \multirow[b]{2}{*}{ Item } & \multirow[b]{2}{*}{ Cronbach's alpha } & \multicolumn{2}{|c|}{ On treatment } & \multicolumn{2}{|c|}{$\begin{array}{l}\text { Within first year of } \\
\text { aftercare }\end{array}$} & \multicolumn{2}{|c|}{$\begin{array}{l}>1 \text { st year of } \\
\text { aftercare }\end{array}$} & \multicolumn{2}{|c|}{ Total sample } \\
\hline & & & Mean & SD & Mean & SD & Mean & SD & Mean & SD \\
\hline Treatment Side effects ${ }^{a}$ & 01-08 & 0.78 & 20.0 & 12.7 & 13.9 & 18.4 & 8.2 & 12.1 & 12.5 & 15.2 \\
\hline Treatment satisfaction $^{\mathrm{b}}$ & $09-10$ & 0.85 & 94.8 & 11.9 & 91.8 & 19.9 & 79.5 & 27.6 & 88.2 & 22.6 \\
\hline Future perspective $^{\mathrm{b}}$ & $11-12$ & 0.76 & 48.9 & 29.0 & 54.8 & 25.2 & 70.4 & 26.4 & 60.8 & 27.8 \\
\hline Job problems ${ }^{\mathrm{a}}$ & $13-14$ & 0.80 & 43.7 & 33.2 & 26.4 & 26.4 & 18.5 & 29.9 & 25.4 & 30.9 \\
\hline Family problems ${ }^{\mathrm{a}}$ & 15 & Single item & 38.1 & 38.2 & 29.9 & 33.1 & 26.3 & 31.4 & 28.9 & 32.8 \\
\hline Infertility $^{\mathrm{a}}$ & 16 & Single item & 24.1 & 39.7 & 34.7 & 38.9 & 31.7 & 36.5 & 30.2 & 37.3 \\
\hline Communication $^{\mathrm{b}}$ & 17,21 & 0.62 & 92.2 & 13.7 & 82.0 & 25.9 & 78.0 & 27.0 & 82.9 & 24.5 \\
\hline Body image problems ${ }^{\mathrm{a}}$ & 18 & Single item & 16.1 & 27.6 & 12.2 & 17.6 & 19.4 & 28.0 & 15.5 & 24.5 \\
\hline Sexual activity ${ }^{\mathrm{b}}$ & $19-20$ & 0.79 & 56.0 & 33.1 & 65.6 & 25.0 & 64.8 & 28.6 & 64.2 & 28.0 \\
\hline Sexual problems ${ }^{a}$ & $22-23$ & 0.36 & 11.3 & 23.9 & 24.8 & 29.6 & 15.5 & 22.1 & 20.9 & 26.5 \\
\hline Sexual enjoyment $^{\mathrm{b}}$ & $24-25$ & 0.51 & 76.2 & 27.7 & 77.3 & 25.7 & 72.5 & 26.4 & 73.6 & 26.4 \\
\hline Testicular Implant Satisfaction ${ }^{\mathrm{b}}$ & 26 & Single item & 75.0 & 50.0 & 93.3 & 14.9 & 60.0 & 34.7 & 69.4 & 35.5 \\
\hline
\end{tabular}

${ }^{a}$ Symptom scale (high scores indicate high impairment)

b Functioning scale (low scores indicate high impairment) 
Table 5 EORTC QLQ-TC26 items (Phase III version)

\begin{tabular}{|c|c|}
\hline \# & Item text \\
\hline 1. & Have you lost any hair? \\
\hline 2. & Have you had problems with your sense of taste or smell? \\
\hline 3. & Have you had pain in your stomach area? \\
\hline 4. & Have you had acid reflux? \\
\hline 5. & Have you had tingling or numbness in your fingers or toes? \\
\hline 6. & Have you had skin problems (e.g. itchy, dry)? \\
\hline 7. & Have you had pale/cold fingers or toes? \\
\hline 8. & Did you have problems with hearing? \\
\hline 9. & Were you satisfied with the medical care you received? \\
\hline 10. & $\begin{array}{l}\text { Were you satisfied with the information you received } \\
\text { about your disease or treatment? }\end{array}$ \\
\hline 11. & Did you feel uncertain about the future? \\
\hline 12. & $\begin{array}{l}\text { Have you been anxious about a possible recurrence } \\
\text { of the disease? }\end{array}$ \\
\hline 13. & $\begin{array}{l}\text { Have you had any problems with your job or your education } \\
\text { because of your disease or treatment? }\end{array}$ \\
\hline 14. & $\begin{array}{l}\text { Have you been physically limited as a result of your } \\
\text { disease or treatment? }\end{array}$ \\
\hline 15. & Were you concerned about disruption of family life? \\
\hline 16. & Were you concerned about your ability to have children? \\
\hline 17. & $\begin{array}{l}\text { Can you talk about your disease with your partner or the person } \\
\text { who is closest to you? }\end{array}$ \\
\hline 18. & $\begin{array}{l}\text { Have you felt less masculine as a result of your disease } \\
\text { or treatment? }\end{array}$ \\
\hline 19. & To what extent were you interested in sex? \\
\hline 20. & $\begin{array}{l}\text { To what extent were you sexually active? } \\
\text { (with or without intercourse) }\end{array}$ \\
\hline \multirow[t]{2}{*}{21.} & $\begin{array}{l}\text { Can you talk about sexuality with your partner } \\
\text { or the person who is closest to you? }\end{array}$ \\
\hline & Next questions only in the case of sexual activity: \\
\hline 22. & Did you have difficulty getting or maintaining an erection? \\
\hline 23. & Did you have problems with ejaculation? \\
\hline 24. & To what extent was sex enjoyable for you? \\
\hline \multirow[t]{2}{*}{25.} & Has the sexual relationship with your partner been satisfying? \\
\hline & Answer this question only if you have a testicular implant: \\
\hline 26. & Are you satisfied with your testicular implant? \\
\hline
\end{tabular}

As the relevance of specific QOL issues, in particular treatment side effects, changes from time of diagnosis to aftercare, extensive consideration was given to whether or not to define treatment phase-specific scales. Despite the advantage of avoiding items of potentially limited relevance to the current situation of an individual patient, we decided against multiple versions of the questionnaire, as this would have complicated longitudinal assessments of QOL across the whole disease trajectory. Also, QOL data collected in phase III showed that TC survivors more than 1 year from treatment still reported treatment side effects.

Related to this, a limitation of our study was that a large proportion of patients were in aftercare and were not undergoing active treatment at the time of assessment. While this reflects a characteristic of the TC patient population, it limited collection of patient feedback concerning treatment-related issues. In particular, patients treated with radiotherapy were underrepresented compared to figures from the literature [2]. Also, future changes in treatment strategies (e.g. increasing use of robotic surgery) may lead to a change in QOL issues relevant to TC patients.

Preliminary analysis of scale structure was primarily based on content at this stage. For several scales, Cronbach's Alpha as measure of unidimensionality indicated sufficient item homogeneity. However, the scales Sexual Enjoyment and Sexual Problems were found to have poor internal consistency. This might be due to the abovementioned presence of floor/ceiling effects in our sample, but could also lead to splitting these scales into single items. According to EORTC module development guidelines, definitive scale structure will be determined through field testing in phase IV. For now, we recommend combining these four sexuality items into two scales, as this is strongly suggested by content.

In conclusion, pre-testing of the EORTC QLQ-TC26 has been completed successfully. The developed questionnaire module proved to be applicable for the assessment of TCspecific QOL issues. Currently, the QLQ-TC26 is available in English, Dutch, German, Italian and Spanish. The questionnaire module will be developed further in an international field study (phase IV) investigating dimensionality, re-test reliability, sensitivity to change as well as the convergent and discriminatory validity of the scales.

Acknowledgments We would like to acknowledge Sophie Fossa, Teresa Young, Jane Blazeby, Henning Flechtner, Madeleine King and Alexander Molassiotis for providing fruitful comments throughout the module development procedure. We would like to thank Tim Luckett, Petra Innerkofler, Kristin Harris, the Italian Germ-Cell Cancer Group (U. Basso, Padova; U. De Giorgi, Meldola; A. L. Gentile, Teramo; D. Dongiovanni, Asti; G. Palmieri, Napoli) and the Australian and New Zealand Urogenital and Prostate Cancer Trials Group (I. Olver, G. Toner, P. Grimison, J. Stubbs, A. Boland) for help with data collection. The work of Johannes Giesinger was funded by a grant from the Austrian Science Fund (FWF; \#502).

Conflict of interest The authors declare that they have no conflict of interest.

Open Access This article is distributed under the terms of the Creative Commons Attribution License which permits any use, distribution, and reproduction in any medium, provided the original author(s) and the source are credited.

\section{References}

1. Bethesda, M. (2008). SEER cancer statistics review 1975-2005, in http://seer.cancer.gov/csr/1975_2005/, L. Ries, et al., Editors, National Cancer Institute. 
2. Sokoloff, M. H., Joyce, G. F., \& Wise, M. (2007). Testis cancer. Journal of Urology, 177(6), 2030-2041.

3. Orre, I. J., et al. (2008). Chronic cancer-related fatigue in longterm survivors of testicular cancer. Journal of Psychosomatic Research, 64(4), 363-371.

4. Dahl, A., Mykletun, A., \& Fossa, S. (2005). Quality of life in survivors of testicular cancer. Urologic Oncology, 23, 193-200.

5. Fossa, S. D. (2004). Long-term sequelae after cancer therapysurvivorship after treatment for testicular cancer. Acta Oncologica, 43(2), 134-141.

6. Huddart, R. A., et al. (2005). Fertility, gonadal and sexual function in survivors of testicular cancer. British Journal of Cancer, 93(2), 200-207.

7. Albers, P. et al. (2010). Guidelines on testicular cancer. European Association of Urology.

8. Sundstrom, J., et al. (2001). Management of testicular cancer16 years' experience from southwest Finland. Scandinavian Journal of Urology and Nephrology, 35(1), 21-25.

9. Steiner, H., et al. (2002). Long-term experience with carboplatin monotherapy for clinical stage I seminoma: a retrospective single-center study. Urology, 60(2), 324-328.

10. Westermann, D. H., et al. (2008). Long-term followup results of 1 cycle of adjuvant bleomycin, etoposide and cisplatin chemotherapy for high risk clinical stage I nonseminomatous germ cell tumors of the testis. Journal of Urology, 179(1), 163-166.

11. Dahl, A. A., Mykletun, A., \& Fossa, S. D. (2005). Quality of life in survivors of testicular cancer. Urol Oncol, 23(3), 193-200.

12. Fossa, S. D., et al. (2003). Quality of life in good prognosis patients with metastatic germ cell cancer: a prospective study of the European organization for research and treatment of cancer genitourinary group/medical research council testicular cancer study group (30941/TE20). Journal of Clinical Oncology, 21(6), $1107-1118$

13. Rudberg, L., et al. (2002). Self-perceived physical, psychologic, and general symptoms in survivors of testicular cancer 3 to 13 years after treatment. Cancer Nursing, 25(3), 187-195.

14. Haugnes, H. S., et al. (2010). Cardiovascular risk factors and morbidity in long-term survivors of testicular cancer: a 20 -year follow-up study. Journal of Clinical Oncology, 28(30), 4649-4657.

15. Huddart, R. A., et al. (2003). Cardiovascular disease as a longterm complication of treatment for testicular cancer. Journal of Clinical Oncology, 21(8), 1513-1523.

16. Matos, E., Skrbinc, B., \& Zakotnik, B. (2010). Fertility in patients treated for testicular cancer. Journal of Cancer Survivorship, 4(3), 274-278.

17. Heidenreich, A., \& Hofmann, R. (1999). Quality-of-life issues in the treatment of testicular cancer. World Journal of Urology, 17(4), 230-238.

18. Nord, C., et al. (2003). Gonadal hormones in long-term survivors 10 years after treatment for unilateral testicular cancer. European Urology, 44(3), 322-328.

19. Fegg, M. J., et al. (2003). Subjective quality of life and sexual functioning after germ-cell tumour therapy. British Journal of Cancer, 89(12), 2202-2206.

20. Kuczyk, M., et al. (2000). Sexual function and fertility after treatment of testicular cancer. Current Opinion in Urology, 10(5), 473-477.
21. Ozen, H., et al. (1998). Psychosocial adjustment after testicular cancer treatment. Journal of Urology, 159(6), 1947-1950.

22. Oldenburg, J., Fossa, S. D., \& Dahl, A. A. (2006). Scale for chemotherapy-induced long-term neurotoxicity (SCIN): psychometrics, validation, and findings in a large sample of testicular cancer survivors. Quality of Life Research, 15(5), 791-800.

23. Rutskij, R., et al. (2010). A study of coping in long-term testicular cancer survivors. Psychology Health Medicine, 15(2), 146-158.

24. Tuinman, M. A., et al. (2005). Marital and sexual satisfaction in testicular cancer survivors and their spouses. Supportive Care in Cancer, 13(7), 540-548.

25. Fossa, S. D., Moynihan, C., \& Serbouti, S. (1996). Patients' and doctors' perception of long-term morbidity in patients with testicular cancer clinical stage I. A descriptive pilot study. Supportive Care in Cancer, 4(2), 118-128.

26. Sprangers, M. A., et al. (1998). The European organization for research and treatment of cancer approach to developing questionnaire modules: an update and overview. EORTC quality of life study group. Quality of Life Research, 7(4), 291-300.

27. Vachalec, S., et al. (2001). EORTC item bank guidelines. Brussels: EORTC Publications.

28. Dewolf, L., et al. (2009). EORTC quality of life group translation procedure (3rd ed.). Brussels: EORTC.

29. Greimel, E., et al. (2006). The European organization for research and treatment of cancer (EORTC) quality-of-life questionnaire cervical cancer module: EORTC QLQ-CX24. Cancer, 107(8), 1812-1822.

30. Velikova, G., et al. (2007). The EORTC QLQ-HDC29: A supplementary module assessing the quality of life during and after high-dose chemotherapy and stem cell transplantation. European Journal of Cancer, 43(1), 87-94.

31. Davies, A. H. G., et al. (2006). Development of a disease-specific quality of life questionnaire module for patients with gastrointestinal neuroendocrine tumours. European Journal of Cancer, 42(4), 477-484.

32. Greimel, E., et al. (2003). An international field study of the reliability and validity of a disease-specific questionnaire module (the QLQ-OV28) in assessing the quality of life of patients with ovarian cancer. European Journal of Cancer, 39(10), 1402-1408.

33. Whistance, R. N., et al. (2009). Clinical and psychometric validation of the EORTC QLQ-CR29 questionnaire module to assess health-related quality of life in patients with colorectal cancer. European Journal of Cancer, 45(17), 3017-3026.

34. Litwin, M. S., et al. (1998). The UCLA prostate cancer index: Development, reliability, and validity of a health-related quality of life measure. Medical Care, 36(7), 1002-1012.

35. Cella, D. F., et al. (1993). The functional assessment of cancer therapy scale: Development and validation of the general measure. Journal of Clinical Oncology, 11(3), 570-579.

36. Goldberg, D. P., et al. (1997). The validity of two versions of the GHQ in the WHO study of mental illness in general health care. Psychological Medicine, 27(1), 191-197.

37. Johnson, C., et al. (2010). Development of the European organisation for research and treatment of cancer quality of life questionnaire module for older people with cancer: The EORTC QLQ-ELD15. European Journal of Cancer, 46(12), 2242-2252. 